\title{
Application of Time-temperature Indicator for Monitoring the Shelf-life of Milk Sample
}

\author{
M. P. Amitkumar*, Udaykumar nidoni, Sharanagouda Hiregoudar, \\ K. T. Ramappa and Nagaraj Naik \\ Department of Processing and Food Engineering, College of Agricultural Engineering, \\ Raichur, University of Agricultural Sciences Raichur, India \\ *Corresponding author
}

A B S T R A C T

Keywords

Time-temperature indicators, Total plate count, Activation energy, Milk brand

\section{Article Info}

Accepted:

10 July 2020

Available Online:

10 August 2020
The effect of temperature history on milk sample was monitored by TTIs was investigated. The mathematical model for TTI has been simulated, which expressed the relationship of the colour advancement of TTI's with different temperature during the storage days. The good correlation ( $\mathrm{R}=0.95)$ was found between the $\ln k$ versus $\mathrm{RT}^{-1}$ of the time-temperature indicators. From the investigation, resulted that activation energy of milk sample $E_{a}$ is $28.7 \mathrm{~kJ}^{-\mathrm{mol}^{-1}}$ and activation energy of Time-temperature indicators $E_{a}$ is $21.52 \mathrm{~kJ}^{-\mathrm{mol}^{-1}}$ and both were found on par with activation energy of the milk sample and TTI sunder isothermal storage condition. Hence, application of the TTIs were suitable to predict shelf life of milk samples.

\section{Introduction}

Generally, food products need some sort of packaging during its existence for protection during transportation, handling, storage and use. Increasingly hectic lifestyles are creating new consumer demands from products and packaging, particularly in terms of user convenience (Bulter, 2005). Over past decade new technologies such as, controlled packaging, which includes aseptic and retort packages, MAP/CAP, biodegradable packaging, edible films and coatings, active packaging and smart packaging systems have improved. The intelligent systems are aiming to monitor the quality of the food product or its surrounding environment to predict or measure the shelf-life better than a best before-date (Jong et al., 2005). Temperature and time, widely recognized as major factors influencing the rate of microbial activity in food often deviate from specifications during the manufacturing, distribution, handling and storage. Hence, it is more important to monitor the changes in temperature and time parameters from production to final 
consumption to microbial safety and quality of products.

Temperature control is crucial to the quality and microbiological safety of refrigerated dairy products such as milk, yogurt and cottage cheese. At higher temperature milk spoils rapidly, because rise in temperature to a few degrees can influence the growth rate of microbial load and thus milk needs to be stored at $5{ }^{\circ} \mathrm{C}$ or below to achieve longer shelf-life, due to low temperature can slow down the chemical changes and growth of many bacteria (Paul-Sadhu, 2015). Consumers check 'best before date', which provides an estimate of the shelf life of milk during the purchase, but milk can spoil before the printed expired date. The probable spoilage microorganisms affecting the quality of pasteurized milk are psychrotrophs, spore forming and also due to microbial enzymatic degradation during storage ( $\mathrm{Lu}$ et al., 2013). The microbiological standard for milk varies from country to country. In India, the acceptable microbiological limit for pasteurized milk is $3 \times 10^{4}$ to $5 \times 10^{4} \mathrm{CFU} / \mathrm{mL}$ (FSSAI, 2015).

\section{Time Temperature Indicators (TTIs)}

Time temperature indicators or integrators (TTIs) are defined as simple, cost-effective and user-friendly devices to monitor, record, and cumulatively indicate the overall influence of temperature history on the food product quality from the point of manufacture up to the point of consumption (Toukis and Labuza, 1989; Giannakourou et al., 2005).

The main advantages of TTIs are of low cost and can easily be integrated in packaging. TTIs are easily measurable "smart labels", which visually reflect the temperature history of food products depending on time and temperature changes and because of this, TTIs can be used extensively in food packaging.
The TTIs based mechanism in food packaging could lead to a better monitoring of cold chain, development of stock rotation, reduction of food waste and ultimately effective shelf-life management (Stergiou, 2018). The TTIs, have capability to provide information on quality of temperature sensitive food products to the consumers. Thus, prevents the manipulation between the consumer and retailer shops and encourages sales as well as promotes company's brand in market and ensures the good quality of food product reaches to the consumers. It is reported that, the use of indicators as quality control devices for milk could be used to predict milk spoilage (Mistry and Kosikowski, 1983).

\section{Materials and Methods}

Time-temperature indicators developed based on Timestrip ${ }^{\circledR}$ Plus ${ }^{\mathrm{TM}}$ capillary technology platform (Timestrip UK Ltd, Sheraton House, Castle Park, Cambridge CB3 0AX, United Kingdom) were studied in this investigation. These indicators come with self-adhesive labels of dimensions $40 \times 19 \times 0.5 \mathrm{~mm}$. Timestrip time-temperature indicators (TP170: threshold $-20^{\circ} \mathrm{C}$, TP077: threshold 0 ${ }^{\circ} \mathrm{C}$, and 15302000625: threshold $10^{\circ} \mathrm{C}$ ) with response time of $8 \mathrm{~h}$ and (TP076: threshold $5^{\circ} \mathrm{C}$ ) with response time of $12 \mathrm{~h}$, respectively are shown in Plate 1. The Shubham gold milk of (5\% fat) taken from KMF outlet, Raichur and taken for conducting experiment on different storage temperature.

For Shubham gold milk, appropriate dilutions $\left(10^{3}\right.$ to $\left.10^{7}\right)$ were carried out and duplicate pour plates were prepared using standard plate count agar as media. Standard Method Agar, incubated at $30{ }^{\circ} \mathrm{C}$ for $48 \mathrm{~h}$, was used to determined total plate counts. All counts were expressed as log colony forming units (CFU) per mL milk (Grisius et al., 1987). 
Every two days interval, observe the color advancement of each TTIs kept in respective storage and note it down with help of vernier scale. Along microbial analysis such as total plate count was also carried out in triplicate for each treatment on Shubham gold milk samples up to 28 days storage period.

\section{Colour advancement of the time temperature indicators}

The Time temperature indicators of $-20,0,5$ and $10{ }^{\circ} \mathrm{C}$ were pasted on the top of the each Shubham gold milk samples and kept in refrigerated storage conditions such as $-20,0$, 5 and $10{ }^{\circ} \mathrm{C}$, respectively. Activate the time temperature indicators in room temperature by squeezing the blisters on the each TTIs. The activation line was appeared as "ON" on the window of the indicators and thereafter attached to Shubham gold milk of (5\% fat), each with activated TTI's of -20 and $0{ }^{\circ} \mathrm{C}$ were kept in deep freezer, $5{ }^{\circ} \mathrm{C}$ were kept in top and $10{ }^{\circ} \mathrm{C}$ in the bottom of the refrigerator at storage temperature of $-20,0,5$ and $10{ }^{\circ} \mathrm{C}$, respectively and maintained in an isothermal condition. The time-temperature indicator's response reflects the storage history of a shubham gold milk sample.

The distance of blue dye movement on surface of TTI's window was measured by using vernier caliper/slide caliper. In TTI's window, displayed hours were replaced by distance in $\mathrm{mm}$. Initially "ON" on the bluster in the window of TTI as $0 \mathrm{~mm}$ was considered which indicated as initial/ starting point and at the end of the TTI's window, $8 \mathrm{~h}$ considered as distance of 8.78, 11.64 and 6.14 $\mathrm{mm}$ (measured from starting point) in $-20{ }^{\circ} \mathrm{C}$, $5{ }^{\circ} \mathrm{C}$ and $10{ }^{\circ} \mathrm{C}$ TTI, respectively which was indicated as end point. Similarly, as in $0{ }^{\circ} \mathrm{C}$ TTI, $12 \mathrm{~h}$ was considered as distance of 7.36 $\mathrm{mm}$ (measured from starting point) as end point which was measured by using vernier caliper (Marta, 2017).

\section{Results and Discussion}

\section{The Kinetics of fresh milk}

Constant temperature tests showed that at different storage temperatures, the microbial load of selected milk samples had different growth rates of change, as shown in Fig1. Using the microbial load as an indicator of quality of milk samples $\left(\mathrm{M}_{1}\right)$ stored at $-20,0$, 5 and $10{ }^{\circ} \mathrm{C}$ under storage temperature, respectively the shelf life was influenced as 26, 16, 8 and 6 day for milk sample $M_{1}$ (i.e. the microbial load was higher than $4.30 \mathrm{log}$ CFU/mL (FSSAI, 2015)).

Milk is spoiled by microbial growth and follows first order reaction in kinetics ( $\mathrm{Fu}$ et al., 1991).So the equation for TPC growth rate reaction is

$\ln \mathrm{N}=\ln \mathrm{N}_{\mathrm{o}}+\mathrm{kt} \ldots$

where, $\mathrm{N}$ is final microbial population (log $\mathrm{CFU} / \mathrm{mL}$ )

$\mathrm{N}_{\mathrm{o}}$ is initial microbial population (log $\mathrm{CFU} / \mathrm{mL}$ )

$\mathrm{k}$ is the reaction rate $\left(\mathrm{d}^{-1}\right)$

$t$ is the days of storage (d)

So, considering the equation (1) of first order reaction for growth rate of microbial load and the reaction rate " $k$ " value for milk samples stored at $-20,0,5$ and $10{ }^{\circ} \mathrm{C}$, respectively can be obtained. Take linear regression by plotting $\ln (\mathrm{N})$ versus $1 / \mathrm{RT}$ of milk samples stored at $-20,0,5$ and $10{ }^{\circ} \mathrm{C}$, respectively and established the curve between $\ln (\mathrm{N})$ versus 1/RT and obtained the reaction rate of TPC growth in shubham gold milk at $-20,0,5$ and $10{ }^{\circ} \mathrm{C}$, respectively $\mathrm{k}_{-20^{\circ} \mathrm{C}}$ is $0.01321 \mathrm{~d}^{-1}, \mathrm{k}_{0}{ }^{\circ} \mathrm{C}$ is $0.0229 \mathrm{~d}^{-1}, \mathrm{k}_{5}{ }^{\circ} \mathrm{Cis} \quad 0.04524 \mathrm{~d}^{-1}$ and $\mathrm{k}_{10^{\circ} \mathrm{C}}$ is $0.06032 \mathrm{~d}^{-1}$. 
Table.1 Treatment details of time-temperature indicators for Shubham gold milk (5 \% fat)

\begin{tabular}{|c|l|}
\hline Treatment & \multicolumn{1}{|c|}{ Details } \\
\hline $\mathbf{T}_{\mathbf{1}} \mathbf{M}_{\mathbf{1}}$ & TTI $\left(-20^{\circ} \mathrm{C}\right)$ pasted on $\mathrm{M}_{1}(5 \%$ fat and $9 \% \mathrm{SNF})$ \\
\hline $\mathbf{T}_{\mathbf{2}} \mathbf{M}_{\mathbf{1}}$ & TTI $\left(0^{\circ} \mathrm{C}\right)$ pasted on $\mathbf{M}_{1}$ \\
\hline $\mathbf{T}_{\mathbf{3}} \mathbf{M}_{\mathbf{1}}$ & TTI $\left(5^{\circ} \mathrm{C}\right)$ pasted on $\mathbf{M}_{1}$ \\
\hline $\mathbf{T}_{4} \mathbf{M}_{\mathbf{1}}$ & TTI $\left(10^{\circ} \mathrm{C}\right)$ pasted on $\mathbf{M}_{1}$ \\
\hline
\end{tabular}

Fig.1 TPC growth in shubham gold milk in the range of $-20,0,5$ and $10{ }^{\circ} \mathrm{C}$



Fig.2 Reaction Rate of TPC growth in shubham gold milk at -20, 0, 5 and $10{ }^{\circ} \mathrm{C}$

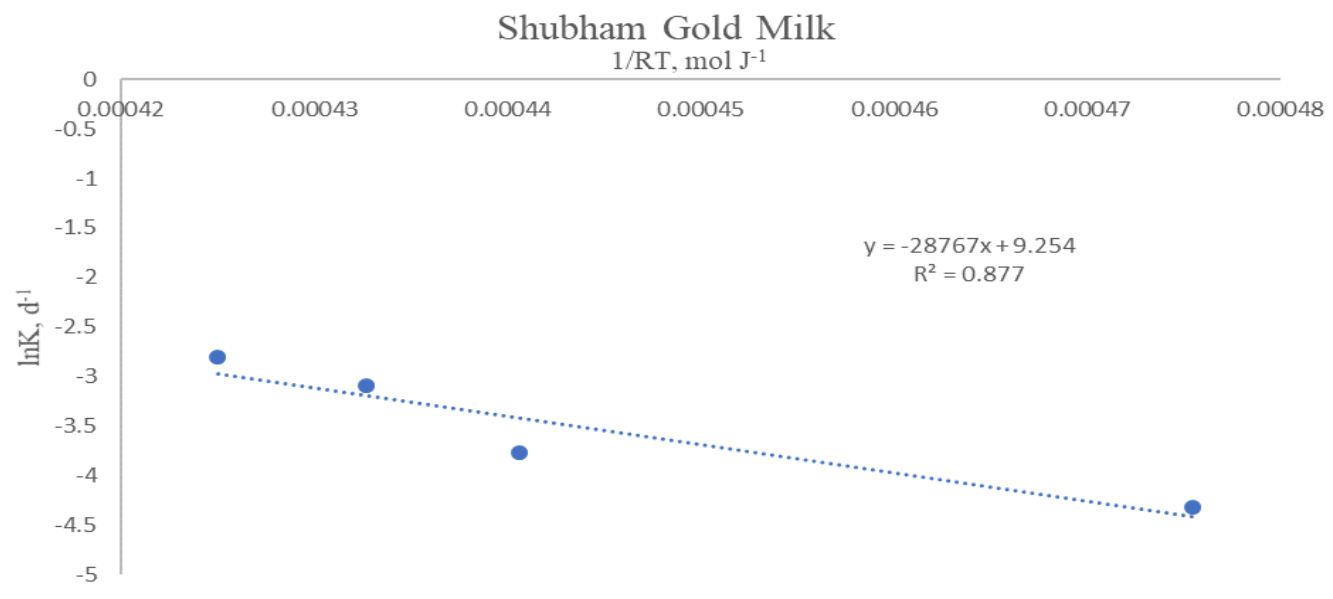


Fig.3 Colour advancement of TTIs with days at $-20,0,5$ and $10{ }^{\circ} \mathrm{C}$

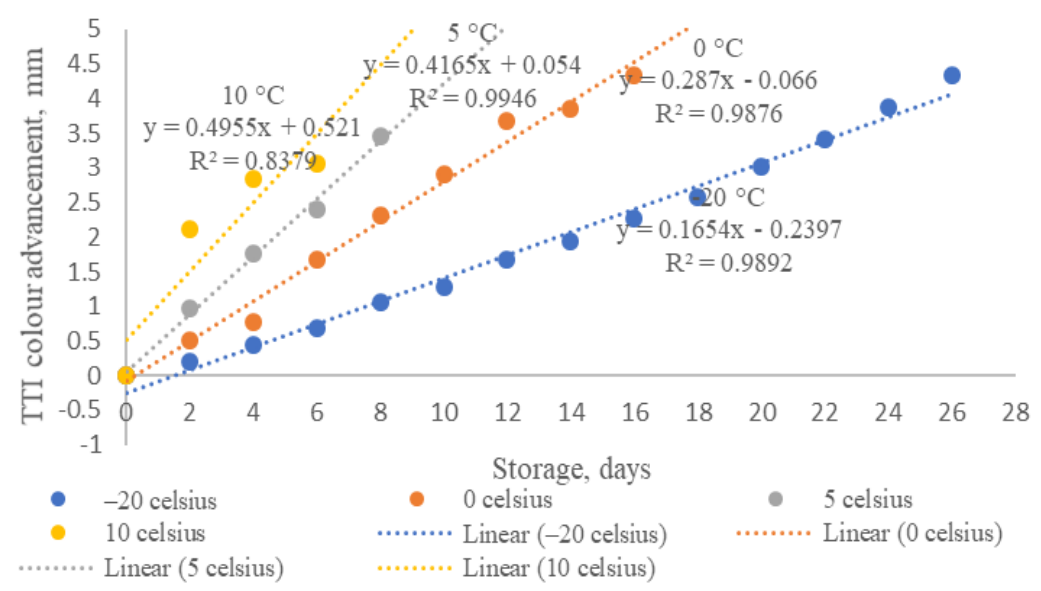

Fig.4 Plot between the $\ln k$ versus $\mathrm{RT}^{-1}$ for TTIs of $-20,0,5$ and $10{ }^{\circ} \mathrm{C}$

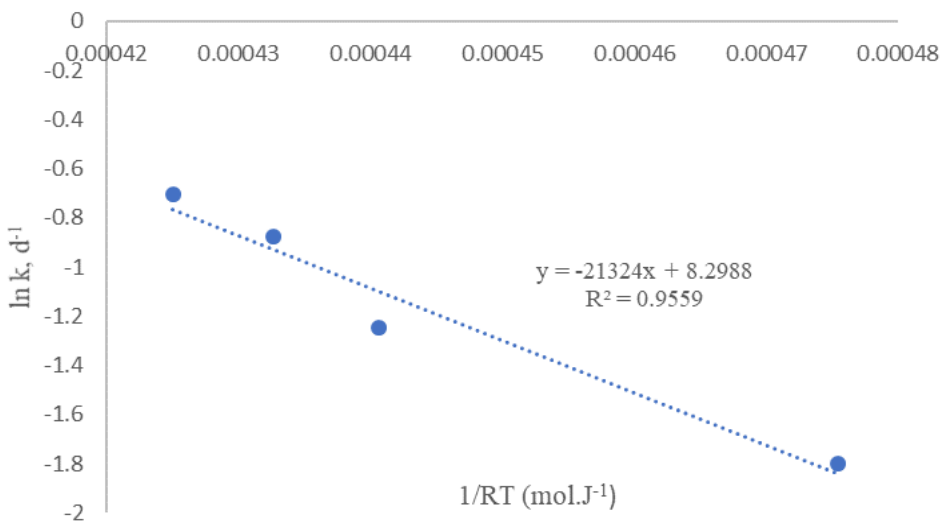

Considering the Arrhenius equation is as follows

$$
\ln \left(\mathrm{N} / \mathrm{N}_{0}\right)=\mathrm{kt}=\mathrm{k}_{0} \exp \left[-\frac{\mathrm{E}_{\mathrm{A}}}{\mathrm{RT}}\right] \mathrm{t}
$$

equating the by applying the $\ln$ on both side of the equation 2 , then obtained equation

$$
\ln \mathrm{k}=\ln \mathrm{k}_{\mathrm{o}}-\frac{\mathrm{E}_{\mathrm{a}}}{\mathrm{RT}}
$$

Plot the curve between the $\ln \mathrm{k}$ vs $(\mathrm{RT})^{-1}$ as shown in fig 2 and we get equation as follows.

$$
\operatorname{lnk}=9.254+2.87 \times 10^{4} \mathrm{RT}^{-1}
$$

The equation (4) shows that activation energy using the microbial load in the milk sample, that is, $E_{a}$ is $28.767 \mathrm{~kJ} \mathrm{~mol}^{-1}$, $\ln \mathrm{k}_{\mathrm{o}}$ is 9.254 and $\mathrm{k}_{\mathrm{o}}$ is $1.04 \times 10^{4} \mathrm{~d}^{-1}$. 
Dynamics of time-temperature indicators (TTIs)

TTIs are used to monitor the quality of fresh milk samples, the activation energy of the TTIs should closely match that of fresh milk. For TTIs pasted on milk samples $M_{1}$, using least square method and fitting the colour advancement of TTIs value ' $x$ ' (which is the diffusion length of colour) and storage days. The reaction rates of TTIs pasted on milk samples were obtained and are as follows: $\mathrm{k}_{-20}$ ${ }^{\circ} \mathrm{C}=0.165, \mathrm{k}_{0}{ }^{\circ} \mathrm{C}=0.287, \mathrm{k}_{5}{ }^{\circ} \mathrm{C}=0.416, \mathrm{k}_{10}{ }^{\circ} \mathrm{C}=$ 0.495 day $^{-1}$ for milk samples $M_{1}$ as shown in Fig 3.

According to Arrhenius model, plotted between the curve of $\ln (\mathrm{k})$ versus $1 / \mathrm{RT}$, as shown in Fig 4, which shows the good correlation $\mathrm{R}^{2}=0.9559$ and curve equation as follows

$$
\ln k=8.298-2.132 \times 10^{4} \mathrm{RT}^{-1}
$$

The equation (5) indicated that the slope of straight line was the activation energy of TTIs pasted on milk samples, that is, $E a$ is 21.32 $\mathrm{kJ} . \mathrm{mol}^{-1}, \ln \mathrm{k}_{\mathrm{o}}$ is 8.298 .

To use TTIs on an actual product, it is important to ensure that it has the same or similar activation energy $E_{a}$ with the product. According to Lu et al., (2013), Taoukis and Labuza proposed in 2001that when the $E_{a}$ difference between product and TTIs was less than $25 \mathrm{~kJ} / \mathrm{mol}$, TTI could be more accurately applied to the product.

After analyzing equation 4 and 5, the kinetic parameters of the product in Fig 2. and TTIs in Fig 4, it was noticed that activation energy difference between TTIs and the milk samples was less than $25 \mathrm{~kJ} / \mathrm{mol}$, in accordance with the theory of Lu et al., (2013), hence the TTIs can be applied to milk samples.
In conclusion the modelling principles from chemical kinetics can be used to derive a prediction model for changes in food quality based on observed response of a timetemperature indicators. Storage temperature and the duration of storage days influenced the quality of milk samples. The use of TTI would be beneficial to the distributor to assess the information of how much temperature variation occurred and to the consumer because error would result in less usable milk discarded. It concluded that TTI was found to be best for estimating the quality changes in milk samples from colour advancement of TTIs.

\section{References}

Butler, P., 2005,Smart Packaging. ID Tech Ex, Cambridge, UK. Food Safety and Standards (Food Products Standards and Food Additives) Regulation, 2015.

Fu, B., Taoukis, P. S. and Labuza, T. P., 1991, Predictive microbiology for monitoring spoilage of dairy products with time-temperature integrators. Journal of Food Science, 56 (5): 12091215.

Giannakourou, M. C., Koutsoumanis, K. and Toukis, P. S., 2005, Field evaluation of the application of time temperature integrators for monitoring fish quality in the chill chain. International Journal of Food Microbiology, 102(3): 323-336

Grisius, R., Wells, J. H., Barrett, E. L. and Singh, R. P., 1987, Correlation of time temperature indicator response with microbial growth in pasteurized milk. Journal of Food Processing and Preservation, 11(4): 309-324

Jong, DE. A. R., Boumans, H., Slaghek, T., Van Veen, J., Rijk, R. and Van Zandvoort, M., 2005, Active and intelligent packaging for food: is it the future? Food Additives and Contaminants, 22(10): 975-979. 
Lu, B. L., Zheng, W., Lv, Z. and Tang, Y., 2013, Development and application of time-temperature indicators used on food during the cold chain logistics. International Journey of Packaging Technology and Science, 26(1): 80-90.

Marta, B., 2017, Shelf-life monitoring of food using time-temperature indicators (TTI) for application in intelligent packaging. Towaroznawcze Probkemy Jakosci, 2(51): 75-85.

Mistry, V. V. and Kosikowski, F. V., 1983, Use of time-temperature indicators as quality control devices for market milk. Journal of Food Protection, 46(1): 52-
57.

Paul-Sadhu, S., 2015, Impact of low refrigeration temperature on colour of milk. Acta Alimentaria, 45(3): 390-397.

Stergiou, F., 2018, Effective management and control of the cold chain by application of Time Temperature Indicators (TTIs) in food packaging. Journal of Food and Clinical Nutrition., 1(1):12-15.

Taoukis, P. S. and Labuza, T. P., 1989, Application of time temperature indicators as shelf-life monitors of food products. Journal of Food Science, 54(4): 783-788.

\section{How to cite this article:}

Amitkumar, M. P., Udaykumar nidoni, Sharanagouda Hiregoudar, K. T. Ramappa and Nagaraj Naik. 2020. Application of Time-temperature Indicator for Monitoring the Shelf-life of Milk Sample. Int.J.Curr.Microbiol.App.Sci. 9(08): 196-202.

doi: https://doi.org/10.20546/ijcmas.2020.908.022 